OPEN ACCESS

Edited by:

Chibundu Ngozi Ezekiel,

Babcock University, Nigeria

Reviewed by:

Keith Warriner

University of Guelph, Canada

Maurice Monjerezi,

University of Malawi, Malawi

*Correspondence:

Erika A. Warnatzsch

erika.warnatzsch@ed.ac.uk

Specialty section

This article was submitted to

Agro-Food Safety,

a section of the journal

Frontiers in Sustainable Food Systems

Received: 05 August 2020

Accepted: 27 October 2020

Published: 25 November 2020

Citation:

Warnatzsch EA, Reay DS, Camardo Leggieri M and Battilani P (2020) Climate Change Impact on Aflatoxin Contamination Risk in Malawi's Maize

\section{Climate Change Impact on Aflatoxin Contamination Risk in Malawi's Maize Crops}

\author{
Erika A. Warnatzsch ${ }^{1 *}$, David S. Reay ${ }^{1}$, Marco Camardo Leggieri ${ }^{2}$ and Paola Battilani ${ }^{2}$ \\ ${ }^{1}$ School of GeoSciences, The University of Edinburgh, Edinburgh, United Kingdom, ${ }^{2}$ Faculty of Agricultural, Food and \\ Environmental Sciences, Università Cattolica del Sacro Cuore, Piacenza, Italy
}

Malawi is one of the poorest countries in the world, with high levels of malnutrition and little domestic mycotoxin regulation. Domestically grown maize is the largest single source of calories in the country and a large contributor to the economy. This research uses Regional Climate Models (RCMs) to determine the climatic conditions in the three regions of Malawi (Northern, Central and Southern) in 2035 (2020-2049) and 2055 (2040-2069) as compared to the baseline climate of 1971-2000. This climatic data is then used as inputs to the Food and Agriculture Organization's (FAO) AquaCrop model to assess the impact on the growth cycle of two maize varieties grown in each region and sown at three different times during the planting season. Finally, AFLA-maize, a mechanistic model, is applied to determine the impact of these projected changes on the aflatoxin $\mathrm{B}_{1}\left(\mathrm{AFB}_{1}\right)$ contamination risk. We find that Malawi's climate is projected to get warmer (by $1-2.5^{\circ} \mathrm{C}$ ) and drier (reduction of $0-4 \%$ in annual rainfall levels) in all regions, although some uncertainty remains around the changes in precipitation levels. These climatic changes are expected to shorten the growing season for maize, bringing the harvest date forward by between 10 and 25 days for the short-development variety and between 25 and 65 days for the long-development variety. These changes are also projected to make the pre-harvest conditions for Malawian maize more favorable for AFB 1 contamination and risk maps for the studied conditions were drawn. Exceedances of EU safety thresholds are expected to be possible in all regions, with the risk of contamination moving northwards in a warming climate.

Keywords: CORDEX, Sub-Saharan Africa, mycotoxins, food security, AFB1, Aspergillus flavus, AquaCrop, AFLA-maize

\section{INTRODUCTION}

Food crops are an ideal substrate for fungal mold growth, and this is a major cause of spoilage in the food supply chain (Adeyeye, 2016). These molds can impact both the quality and quantity of the crop yield, and can contaminate the edible part of the crops with toxic secondary metabolites called mycotoxins (Bhat and Miller, 1991; Magan et al., 2011). Exposure to mycotoxins, either through skin contact, inhalation or ingestion can cause a range of symptoms and illnesses in humans, both acute and chronic, ranging from cold and flu like symptoms to immune deficiency, organ failure, cancer and even death (Peraica et al., 1999; Hussein and Brasel, 2001; Udomkun et al., 2017). The young, elderly and those with compromised immune systems are more vulnerable to the 
negative health effects of mycotoxins (Bennett and Klich, 2003). While early estimates from the Food and Agriculture Organization (FAO) suggested that mycotoxin contamination effected $25 \%$ of global crops, more recent estimates show that this may be as high as 60-80\% (Eskola et al., 2019).

The main food crops grown in Malawi are unfortunately not safe from mycotoxin contamination (Misihairabgwi et al., 2017) and with much of the population reliant on unregulated subsistence farming, and no regulation on levels of mycotoxins found in domestically grown food sold in local markets (Mwalwayo and Thole, 2016), the population is at risk of dangerous levels of mycotoxin exposure. Furthermore, high levels of malnutrition and incidence of communicable diseases such as HIV/AIDS, tuberculosis and malaria (IHME, 2018), make the population of Malawi particularly vulnerable to the adverse health effects of mycotoxin exposure.

The molds which produce mycotoxins tend to flourish in hot and humid environments, therefore the sub-tropical climate of Malawi creates conditions conducive to growth (Misihairabgwi et al., 2017). Multiple drivers impact the type and concentration of mycotoxin which is produced, including the nutritional composition and genetic susceptibility of the host plant, moisture content, humidity, water activity, aeration, temperature, acidity level, fungal population, and physical condition of the crop (e.g., damage due to insects or other stress factors) (Matumba et al., 2014a). However, meteorological conditions are the most important factor in the production of mycotoxins and therefore, climate change is likely to induce significant changes in the distribution, type, and concentration of mycotoxins (Paterson and Lima, 2010).

Little research has so far examined the effect future climate change may have on mycotoxins in Africa as a whole, let alone in specific nations such as Malawi. However, some assessment of current prevalence and impact of mycotoxins in Malawi has been made. The majority of these studies concentrate on aflatoxins due to their significant health impacts and the relative ease of detection (Chipinga, 2014). Aflatoxins are a group of mycotoxins produced primarily by Aspergillus flavus and A. parasiticus, with A. flavus a widespread contaminant in arable agriculture (Payne and Brown, 1998; Santini and Ritieni, 2013). While there are many different types of aflatoxins, studies often concentrate on aflatoxin $\mathrm{B}_{1}\left(\mathrm{AFB}_{1}\right)$ as it is the most toxic of the compounds ${ }^{1}$, and is a known carcinogen, causing liver cancer, growth suppression, immune system modulation, and malnutrition in both humans and livestock (Payne and Brown, 1998; Rushing and Selim, 2019). Due to its ability to suppress the immune system, $\mathrm{AFB}_{1}$ exposure is also believed to be linked with the increased HIV viral load in those infected, and faster progression of the HIV infection to AIDS (Jolly, 2014). While data on the exact impacts of aflatoxin exposure in Malawi are unknown, the Partnership for Aflatoxin Control in Africa (PACA, 2020) estimates that over 2,100 cases of liver cancer and 75,400 healthy life years are lost annually in Malawi due to aflatoxin exposure. In addition to the main health

\footnotetext{
${ }^{1} \mathrm{AFB}_{1}$ has a median lethal dose $\left[\mathrm{LD}_{50}\right]$ for mice in laboratory testing which ranges from 9-60mg of $\mathrm{AFB}_{1}$ per kg of body weight (Almeida et al., 1996).
}

concerns for people involved, this causes an annual loss of up to USD 393.6 million to the local economy (PACA, 2020).

The few studies available that explore the current prevalence of aflatoxin contamination in Malawian food have highlighted a worrying situation. Analysis of a range of locally processed maize-based foods sold in popular Lilongwe markets found multiple incidence of aflatoxins, including $\mathrm{AFB}_{1}$, at concentrations which exceeded EU health safety levels, including in all 36 samples of locally processed maize-based baby foods (Matumba et al., 2014b) (see Supplementary Table 1). With infants being particularly susceptible to the negative effects of aflatoxins, and cereal based foods forming a significant part of many infants' diets, these findings are very concerning.

The presence of different mycotoxins and the levels of mycotoxin contamination differ by climatic region in Malawi. A study by Chipinga (2014) found that the Southern region, which tends to be warmer in all seasons (Met Malawi, 2006), has more incidence of mycotoxin contamination in general, with samples more likely to contain fumonisins, aflatoxins, deoxynivalenol, and/or ochratoxin, while incidences were lower in the relatively cooler Central region, and the contaminant more likely to be zearalenone. These findings are in line with Matumba et al. (2014c) who found that $75 \%$ of samples taken from hotter regions of the country were contaminated with at least one mycotoxin, whereas cooler zones had a much lower incidence of mycotoxin contamination at $17 \%$. These studies highlight that the climatic conditions not only have an important role in whether mycotoxin-producing molds will be present, but also which species will grow and how prolific they will be.

With increasing temperatures and more erratic rainfall predicted (Mittal et al., 2017; Warnatzsch and Reay, 2020), it is likely that climate change will impact mycotoxin occurrence in Malawi in terms of their type, geographic distribution and concentration. These changes may negatively impact the quality and quantity of food grown, and therefore raise key issues for human health, food security, and climate change adaptation. This paper aims to quantify the current and future risk of pre-harvest $\mathrm{AFB}_{1}$ contamination of maize in the three main growing regions of Malawi of this staple food crop.

Aflatoxin risk is a main concern in Malawi and it could become even more serious in the future; predictions highlight an increase in maize contamination in Europe (Battilani et al., 2016), therefore suggesting possible critical scenarios for aflatoxin contamination of maize in other geographic areas. Domestically grown maize represents 48 percent of the calorie intake of Malawi's population, with 32,54, and 14 percent of that maize grown in the Southern, Central and Northern regions, respectively (Arya et al., 2005; FAOSTAT, 2018). A change in contamination risk could therefore have large impacts to food security and safety at regional and national levels and may require anticipatory actions (Battilani et al., 2016). The modeling approach is a crucial tool for policy makers and farmers to support strategic decisions and reinforce aflatoxin management, both of them aimed to prevent human and animal exposure to this compound with acute and chronic toxic effects. 
In each of the three regions, two varieties of maize were chosen for assessment, one slow- and one fast-developing. Three different sowing dates, early, medium and late, were also assessed.

\section{METHODOLOGY}

To assess the potential impact of climate change on the risk of pre-harvest $\mathrm{AFB}_{1}$ contamination of maize crops over time and geographic spread, it was first important to understand how the climate is projected to change in the three regions of Malawi: Southern, Central and Northern. Here we first assess the baseline climate of each region as the 1971-2000 period, and two future time periods representative of the 2035 (2020-2049) and 2055 (2040-2069) climates under Representative Concentration Pathway (RCP) 4.5 and 8.5. These two future time horizons were chosen as they are long enough to allow for adaptation measures to be implemented, and short enough to be relevant to current farmers, consumers, and policy makers.

As an assortment of maize cultivars are grown in Malawi and planting occurs during a "season" rather than on a specific date, this assessment considers the changes in pre-harvest $\mathrm{AFB}_{1}$ contamination risk on two varieties of maize, one with a slowdevelopment and one with a fast-development period, which are sown on three separate dates within the main summer growing season, November 15, December 10 and December 30 (Warnatzsch and Reay, 2020).

A modeling approach was used to predict the risk of $\mathrm{AFB}_{1}$ contamination of each variety of maize in each time-period and region depending on sowing date. The model applied was AFLAmaize, a mechanistic weather-driven model which determines the daily risk of $A$. flavus infection and $\mathrm{AFB}_{1}$ contamination of maize from silk emergence through to harvest (Battilani et al., 2013). This model has been shown to be effective in predicting aflatoxin contamination in maize crops grown in Italy (Battilani et al., 2013), it was effectively used to assess the impact of climate change on mycotoxin risk in Europe (Battilani et al., 2016), and recently the model was successfully adapted to predict $\mathrm{AFB}_{1}$ occurrence in pistachio-nuts in Greece (Kaminiaris et al., 2020). A site-specific validation for Malawi was not managed; however, mechanistic models, such as AFLAmaize, are designed to consider the cause-effect relationship between variables and no calibration is required when used in different geographies (De Wolf et al., 2003; Camardo Leggieri et al., 2013).

To run the AFLA-maize model it was necessary to obtain daily climatic data for each time-period and RCP scenario, as well as information on the crop development, namely the sowing date, the emergence date and the harvest date. The methodologies for determining these model inputs, and the process for utilizing the model are described in the sections below.

\section{Climatic and Environmental Conditions}

The daily temperature, precipitation and relative humidity data used in this assessment were output from a set of atmospheric Regional Climate Models (RCMs) from the African domain of the Coordinated Regional Climate
Downscaling Experiment (CORDEX) initiative (see list of RCMs in Supplementary Table 2). Within this initiative, all currently publicly available models which provide projections for both RCP 4.5 and 8.5 were selected, with one exception ${ }^{2}$.

Limited by the resolution of the models ${ }^{3}$, and the need to use a rectangular boundary, the assessment includes spatial data that are larger than the actual geographical boundary of the three Malawi regions, and some overlap in the three regions also exists, as shown by the shaded areas in Figure 1.

Direct comparison of individual CORDEX model outputs is possible as the initiative sets a standard grid, domain size, experiment protocols, and data format (Giorgi et al., 2009; Nikulin et al., 2012). However, the CORDEX initiative does not dictate the calendar format resulting in some of the RCMs using a complete 366-day calendar (includes leap-days in relevant years), while others have a 365-day calendar or a 360-day calendar (assumes all months are 30 days). Before any direct comparisons or ensemble means could be calculated from the daily data outputs, it was necessary to make all the calendar formats the same. There is no standard method to do this, however the models used in this assessment require either a 365-day year (for AquaCrop) or 366-day year(for AFLA-maize). Therefore, in order to make the calendar formats comparable the methodologies established by Warnatzsch and Reay (2020) were applied.

The ability of these RCMs to hindcast daily mean temperature in Central Malawi was evaluated in a previous study. It was found that, while they are able to replicate relative changes in temperature well, they are not able to adequately simulate absolute temperatures (Warnatzsch and Reay, 2019). To account for this modeling bias, the temperature and precipitation projections were re-baselined using methods applied by the Met Office's United Kingdom Climate Projections (UKCP18) (Met Office, 2018) and the observed datasets detailed in Supplementary Table 3 (Warnatzsch and Reay, 2020). An adequate observed database for historical relative humidity could not be found for Malawi and as such, the relative humidity data have not been re-baselined and the authors acknowledge that these data are a source of uncertainty.

As reference evapotranspiration (ETo) is not a climatic variable, the CORDEX-Africa models do not have an output for it. The reference evapotranspiration data for each time period were therefore determined using the FAO's Penman-Monteith (FPM) method (Allen et al., 1998a,b), details of which can be found in the Supplementary Material. This methodology was tested for application in Malawi (Wang et al., 2011) and Southern Malawi more specifically (Ngongondo et al., 2012) and deemed appropriate for use.

Data for leaf wetness, an important variable for determining mycotoxin risk, were also not available for any region or time

\footnotetext{
${ }^{2}$ At the time of writing there was one additional RCM available that met these criteria, HIRHAM5_NorESM1-M, however this model has been excluded from this study. Based on the findings of Warnatzsch and Reay (2019), this RCM is a major outlier and does not simulate Malawi's temperature or precipitation well.

${ }^{3}$ All the RCMs used have a 0.44 -degree $\left[\sim 50 \mathrm{~km}^{2}\right]$ resolution.
} 

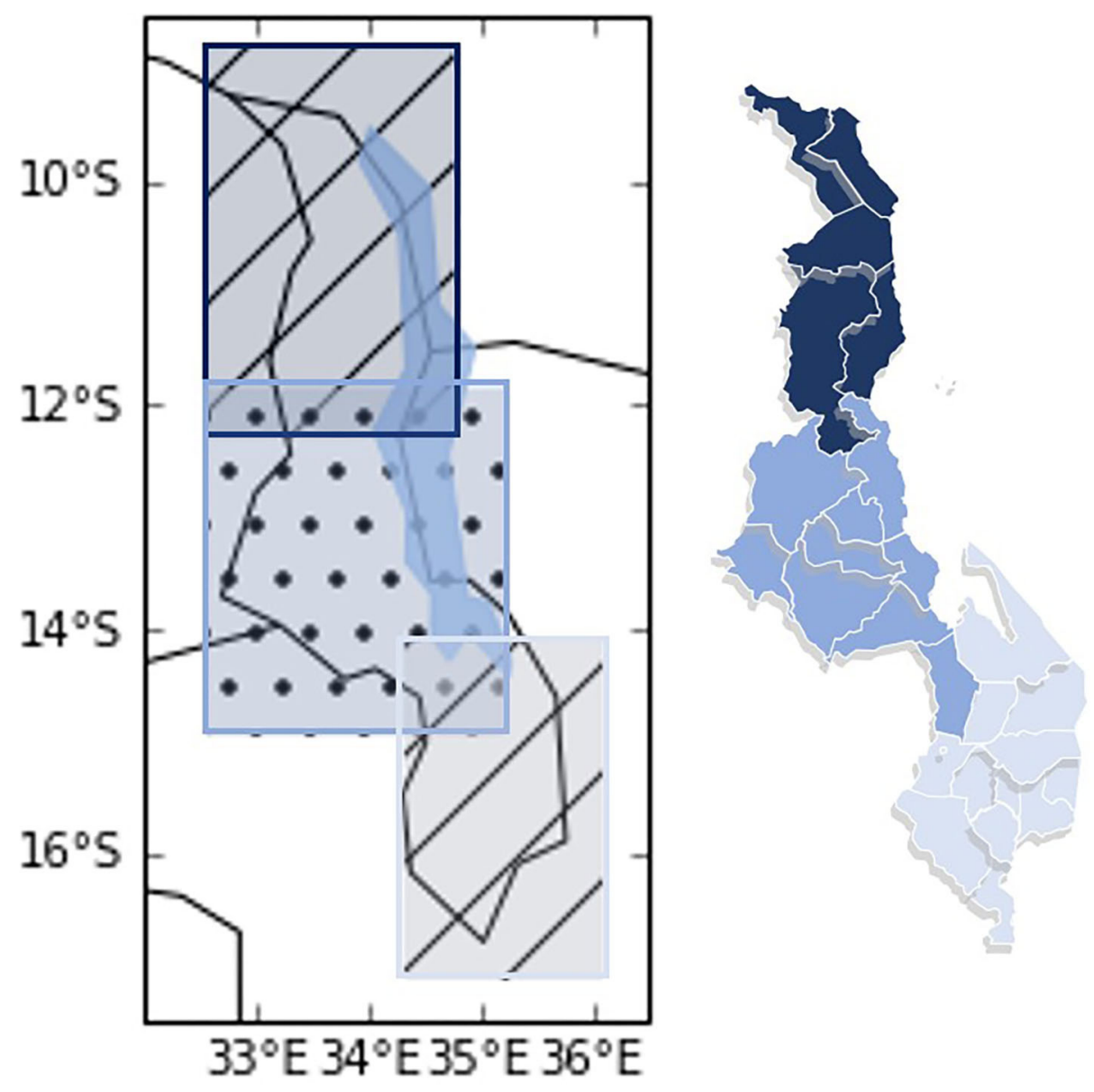

FIGURE 1 | Map of Malawi represented with geographical coordinates (left) and based on actual land boundary (right). The map on the left shows the data boundary used in this assessment. Northern Malawi is indicated by the hatched area at the top (32.5 to 35 degrees East and -8.5 to - 12.5 degrees South), Central Malawi is indicated by the dotted area in the center (32.5 to 35.5 degrees East and -11.5 to -15 degrees South), and Southern Malawi is indicated by the hashed area at the bottom (34 to 36.5 degrees East and -14 to -17.5 degrees South). Black lines show national borders and the solidly shaded gray-blue area is Lake Malawi. The map on the right shows the actual land boundary and the district borders (white lines) with Northern Malawi in the darkest shade, Central Malawi in the mid-shade, and Southern Malawi in the lightest shade.

frame in Malawi. As such, an established empirical model to simulate leaf wetness was applied. This model assumes that if relative humidity was $\geq 90 \%$, or there was any precipitation ( $\geq 0 \mathrm{~mm}$ ) during that day, the leaf wetness would be equal to one (1), otherwise it was assumed to be zero (0). Evaluation of this model in various parts of the world has found that, in the absence of measured data, this empirical model performed better than other methods, although some over or under estimation was observed (Sentelhas et al., 2008). While the authors acknowledge that this is a source of uncertainty, Battilani et al. (2016) carried out a sensitivity analysis which found that the model accuracy was not significantly affected by adjusting leaf wetness within a realistic range.

Previous analysis on the performance of climate models to simulate precipitation in Malawi have found the model outputs to be highly divergent and not well-correlated to observed precipitation levels (Mittal et al., 2017; Warnatzsch and Reay,
2019). However, in both the Warnatzsch and Reay (2019) and Mittal et al. (2017) a clustering of model outputs was seen around the ensemble mean, making this scenario more likely than either a minimum or maximum scenario. Based on these findings, the current study assessed future impacts on Malawi's three regions using an ensemble mean precipitation scenario. With regards to temperature, Warnatzsch and Reay (2019) found that the ensemble average adequately represented the temperature records of Malawi once adjusted for the bias, as described above. Therefore, our impact assessment was based on climatic scenarios built upon the bias-adjusted ensemble average outputs for daily precipitation rate, temperature, the ensemble mean relative humidity rates, and calculated reference evapotranspiration and leaf wetness. The full details of these climate scenarios can be found in Supplementary Tables 4, 5 .

All data were formatted and output from the RCMs using a Python interface and a variety of open source Python libraries 
and packages. The code used for each assessment can be found in the author's GitHub repository ${ }^{4}$.

\section{Crop Development}

A crop model (AquaCrop) was used to determine the emergence date and the harvest date of two varieties of maize (slow- and fast-development) under the different climatic conditions (set out in section Climatic and Environmental Conditions) and initial sowing dates in each region of Malawi. The calibration of AquaCrop in this analysis was based on earlier calibration carried out by Warnatzsch and Reay (2020). Full details of the calibration for the two crop models is given in Supplementary Tables 6, 7.

With a broader geographic range, the calibration of AquaCrop for soil in this study differed slightly from Warnatzsch and Reay (2020). The dominant soil texture in Malawi is classified as sandy clay loam, accounting for over two thirds of the soil distributed across the country (Li et al., 2017). Li et al. (2017) found that the Northern Region also had a sandy loam texture in a tenth of the soil, while the Central Region had just under a tenth of its soil texture described as sandy loam. Other soil textures were found to account for only a small proportion of the soils. Therefore, the AquaCrop model was run using the sandy clay loam, sandy loam and sandy clay default AquaCrop soil models. However, the soil choice was found to have no impact on the crop development dates in any region.

\section{Aflatoxin Contamination Risk Assessment}

The mechanistic model, AFLA-maize, was used to predict $\mathrm{AFB}_{1}$ contamination risk of two different maize varieties grown in the three regions of Malawi using crop development dates and the climate scenarios creating using the methodology described in sections Climatic and Environmental Conditions and Aflatoxin Contamination Risk Assessment above. The original AFLA-maize model required hourly meteorological data input (Battilani et al., 2013), however this was not available for Malawi. Therefore, the methodology applied by Battilani et al. (2016) to adapt the model to work with daily meteorological data was used in this analysis. The sensitivity of the AFLAmaize model to this adaptation was tested by Battilani et al. (2016, supplementary material) and the results were found to be comparable.

\section{RESULTS}

\section{Projected Climate Change in Malawi}

Malawi's current climate is classified as sub-tropical (Met Malawi, 2006). It has two distinct seasons: a warm and wet season in the spring and summer (October to April) and a cooler, dry season in the autumn and winter (May to September). Historic trends in Malawi's climate are shown in Supplementary Figure 1. Temperatures fluctuate by an average of $11^{\circ} \mathrm{C}$ over the course of the day, with a larger range in the winter months than the summer. On average, the Northern Region of the country is the coolest, and the Southern Region is the warmest. Precipitation

${ }^{4}$ The author's GitHub directory can be found at: https://github.com/ ErikaWarnatzsch/Maize-Aflatoxin-Risk. levels vary by region and season, with almost no rain in any region during the autumn and winter months (April-October). During the spring and summer months (November-March), the Northern and Central Regions tend to see more rainfall than the Southern Region. With reference evapotranspiration linked to temperature, a similar trend is seen for this variable; overall reference evapotranspiration is higher in the spring and summer, and lower in the autumn and winter. As temperatures decrease with latitude, reference evapotranspiration rates are highest in the Southern Region, and lowest in the Northern Region. Relative humidity levels are also tied to temperature and precipitation, although the annual trend shows a lag response, with the highest rates in February and lowest in October.

The seasonality that Malawi experiences is expected to continue under both RCP 4.5 and RCP 8.5 for the 2020-2049 and 2040-2069 periods. However, temperatures are set to increase in all regions and scenarios (see Table $\mathbf{1}$ ).

With increasing temperatures, rates of reference evapotranspiration are also projected to increase slightly in all future time periods and regions (see Table 2). The ensemble mean shows a small decreasing trend in precipitation rate and relative humidity in all future scenarios and regions. The small change in precipitation $( \pm 5 \%)$ is supported by around half of the model projections, with a larger number projecting a reduction rather than an increase in precipitation in all future scenarios and regions.

\section{Changes in Crop Development}

Projected climate change for the 2020-2049 and 2040-2069 periods, as described in section Projected Climate Change in Malawi, is not expected to have a significant impact on the date of emergence of either the fast- or slow-developing maize varieties considered here; shifting the date forward by an average of 1 day (maximum 2 days). However, the impact on the date of harvest is larger. Both maize varieties show little difference between the two future time horizons examined in either absolute or relative terms. However, the RCP scenario does impact the results for both varieties and all sowing dates with RCP 8.5 scenario leading to a shorter development time than the RCP 4.5 scenario in the same time period (see Supplementary Tables 8, 9 for full results).

Figure 2 shows the absolute (Figure 2A) and relative (Figure 2B) change in the number of days between sowing and harvest for the two varieties of maize in the three regions. For all future scenarios in all three regions and sowing dates, the time to harvest for the slow-development variety of maize shortens by a larger number of absolute days than the fastdevelopment variety. However, on relative terms, the impact that future climate change has on the time to harvest depends on sowing date and variety. The slow-development maize variety shows a smaller relative advance in harvest timing with later sowing dates in the Northern and Central regions, but this trend is not followed in the Southern region. For the fast-development maize variety, the relative impact on the development time to harvest is smaller with earlier sowing dates in all regions. 
TABLE 1 | The historic annual mean, minimum, and maximum surface air temperatures (Tas) in the three regions of Malawi for the 1971-2000 period, and the Regional Climate Model (RCM) ensemble mean projected change ( $\Delta$ ) in temperature for the 2035 (2020-2049) and 2055 (2040-2069) climate periods under the Representative Concentration Pathway (RCP) 4.5 and 8.5 scenarios.

\begin{tabular}{|c|c|c|c|c|c|c|c|c|c|c|}
\hline & & \multicolumn{3}{|c|}{ Southern } & \multicolumn{3}{|c|}{ Central } & \multicolumn{3}{|c|}{ Northern } \\
\hline \multirow[t]{2}{*}{$\Delta\left({ }^{\circ} \mathrm{C}\right) \mathrm{RCP} 4.5$} & 2020-2049 & 1.4 & 1.4 & 1.0 & 1.4 & 1.4 & 1.4 & 1.4 & 1.4 & 1.4 \\
\hline & 2040-2069 & 1.8 & 1.8 & 1.4 & 1.9 & 1.9 & 1.9 & 1.9 & 1.9 & 1.9 \\
\hline$\Delta\left({ }^{\circ} \mathrm{C}\right) \mathrm{RCP} 8.5$ & 2020-2069 & 1.6 & 1.5 & 1.1 & 1.6 & 1.6 & 1.6 & 1.6 & 1.6 & 1.6 \\
\hline
\end{tabular}

TABLE 2 | The historic precipitation rate, reference evapotranspiration rate (ETo) and relative humidity in the three regions of Malawi for the 1971-2000 period, and the Regional Climate Model (RCM) ensemble mean or calculated projected change ( $\Delta$ ) in these variables for the 2035 (2020-2049) and 2055 (2040-2069) climate periods under the Representative Concentration Pathway (RCP) 4.5 and 8.5 scenarios.

\begin{tabular}{|c|c|c|c|c|c|}
\hline & & & Southern & Central & Northern \\
\hline \multirow{4}{*}{ Precipitation (mm/year) } & Absolute & $1971-2000$ & 1,048 & 1,085 & 1,111 \\
\hline & $\Delta(\%) \mathrm{RCP} 4.5$ & 2020-2049 & $-2 \%$ & $-3 \%$ & $-2 \%$ \\
\hline & $\Delta(\%) \mathrm{RCP} 8.5$ & 2020-2069 & $-1 \%$ & $-3 \%$ & $-3 \%$ \\
\hline & & 2040-2069 & $0 \%$ & $-4 \%$ & $-3 \%$ \\
\hline & & 2040-2069 & $2 \%$ & $5 \%$ & $5 \%$ \\
\hline & $\Delta(\%) \mathrm{RCP} 8.5$ & 2020-2069 & $2 \%$ & $4 \%$ & $4 \%$ \\
\hline & & 2040-2069 & $4 \%$ & $11 \%$ & $7 \%$ \\
\hline \multirow[t]{2}{*}{ Relative Humidity (\%) } & Absolute & $1971-2000$ & $67 \%$ & $66 \%$ & $67 \%$ \\
\hline & $\Delta(\%) \operatorname{RCP} 4.5$ & 2020-2049 & $-2 \%$ & $-2 \%$ & $-2 \%$ \\
\hline
\end{tabular}

\section{Changes in Aflatoxin $B_{1}$ Contamination Risk}

The primary output of the AFLA-Maize model-the aflatoxin risk index (AFI) - indicates the cumulative risk of $\mathrm{AFB}_{1}$ contamination in the crop during its development pre-harvest (Battilani et al., 2016). If AFI $=0$ this indicates that conditions are such that no interaction between the A. flavus and the maize crop was possible, and as such no $\mathrm{AFB}_{1}$ contamination risk is possible. Where the AFI result is larger than zero, then a host interaction is possible, which indicates that $\mathrm{AFB}_{1}$ contamination is also a risk. An AFI $\geq 95$ is considered consistent with an $\mathrm{AFB}_{1}$ contamination equal to or greater than the current European threshold for legal $\mathrm{AFB}_{1}$ contamination, $5 \mu \mathrm{g}$ per $\mathrm{kg}$ (EU, 2006, 2010, 2014). The results of the AFLA-maize analysis are shown in Figures 3, 4 (the numerical data is presented in tabular and graphical format in the Supplementary Table 10 and Supplementary Figure 2).

Use of the baseline climate (1971-2000) indicates $\mathrm{AFB}_{1}$ contamination risk in both maize varieties to be possible in all regions of Malawi, with the AFI lowest in the Northern Region and highest in the South. The model indicates that the EU legal threshold of $5 \mu \mathrm{g} \mathrm{AFB}_{1}$ per $\mathrm{kg}$ is likely to be exceeded in the Southern Region regardless of sowing date or variety of maize, and some exceedances are possible in the Central region. Risk of EU legal threshold exceedances in the Northern region is low under these baseline climate conditions. For both maize varieties, later sowing dates in the Northern and Central regions largely result in higher contamination risk than earlier sowing dates, although this trend is not seen in the Southern region.

In the future climate scenarios examined both varieties of maize show the same general trends: higher concentrations of $\mathrm{AFB}_{1}$ contamination and the risk of exceeding the EU legal threshold moving northward. The trend of later sowing dates resulting in higher contamination risk continues in the Northern and Central region under the future climate scenarios. However, there is still no consistent trend in the Southern region, where sowing date plays a smaller relative role in the changes observed. The only scenario where the maize shows a lower risk of contamination in a future climate relative to the baseline is in the Northern region with the earliest sowing date. This decrease in risk is linked to the shortened development time, which means the A. flavus does not have enough time to grow and produce high 
A

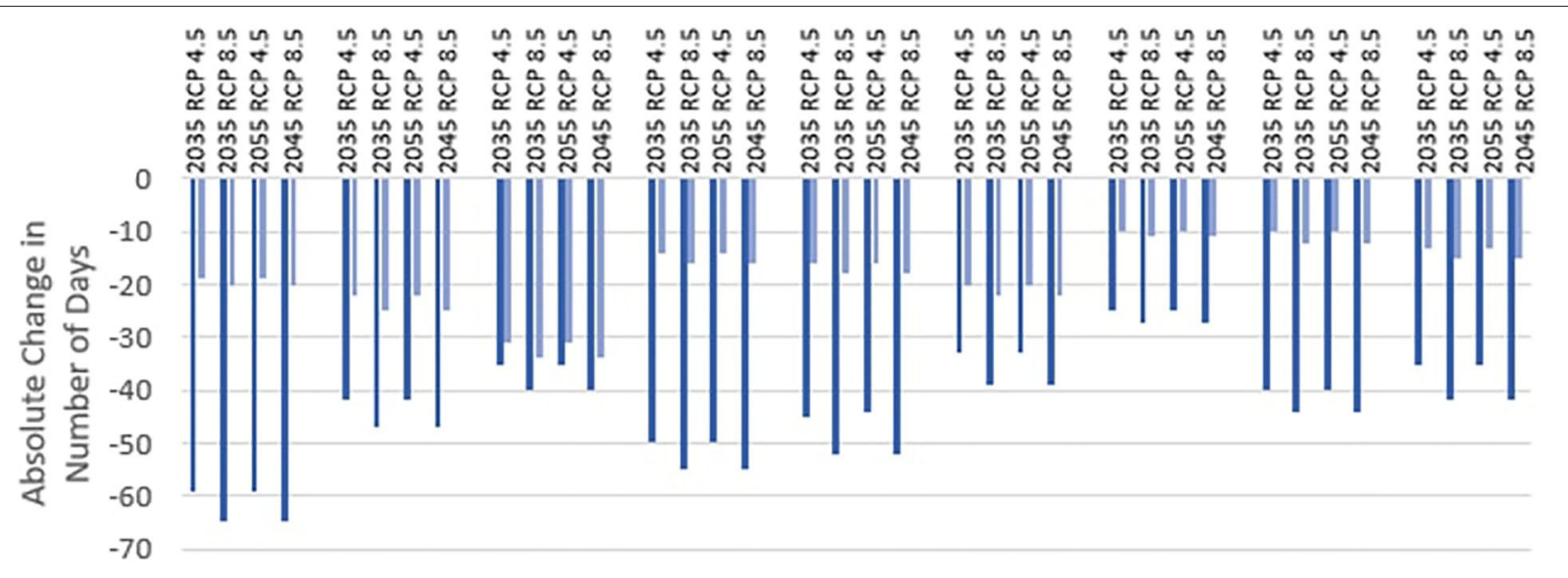

B

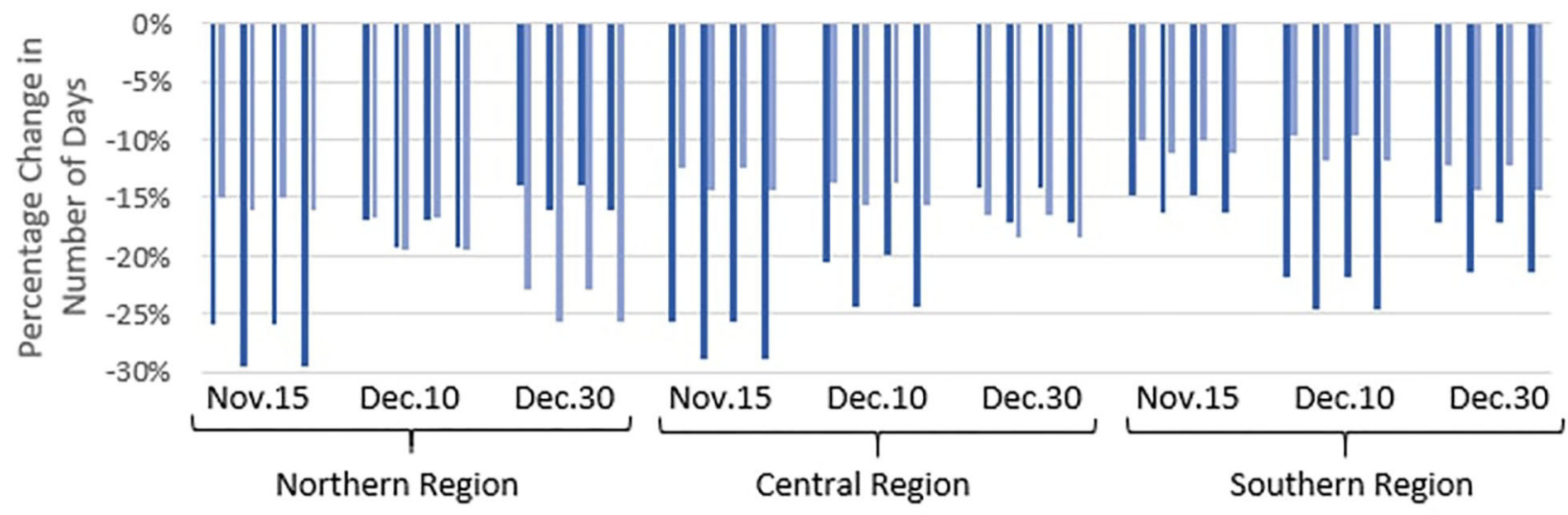

FIGURE 2 | Absolute (A) and relative (B) change in the number of days between sowing date and harvest date for two maize varieties planted on three different sowing dates (November 15, December 10, and December 30) in the three Malawi regions (Northern, Central, and Southern). These data are provided for two future time periods (2020-2049 and 2040-2069) and Representative Concentration Pathways (RCPs) (4.5 and 8.5) and are compared to the baseline period 1971-2000.

levels of $\mathrm{AFB}_{1}$ before the crop is harvested. This is also the reason the future climates under RCP 8.5 do not always show higher contamination risk than the RCP 4.5 climate in the same period; while the future climatic conditions are often more conducive to $\mathrm{AFB}_{1}$ contamination, the crop development is accelerated and therefore the toxin has less time to accumulate.

Similar levels of contamination risk are seen in both varieties of maize under the same climatic and sowing conditions, with no consistently strong trend seen in the Southern or Central regions between varieties. However, in the Northern region, the slow-development maize variety did show slightly higher levels of contamination risk than the fast-development maize variety which again is due to longer periods of time for the toxin to be produced before the time of harvest.

\section{DISCUSSION AND CONCLUSION}

Currently, the majority of maize is grown in the Central region of Malawi, with trade between the regions (FAOSTAT, 2018). We find that future climate change can be expected to increase the risk of pre-harvest $\mathrm{AFB}_{1}$ contamination in maize in all regions of Malawi. The risk of dangerous contamination levels (i.e., above EU legal thresholds) is expected to continue in the Southern region while also expanding northwards into the Central and Northern regions.

Our results are consistent with the findings of previous research which has shown that increasing temperatures, particularly when combined with lower precipitation levels during the early growing season, lead to higher levels of aflatoxin contamination (Battilani et al., 2008; Magan et al., 2011; Medina et al., 2014, 2017; Stepman, 2018). However, with significant uncertainty remaining around future precipitation rates, further analysis should be carried out with a range of precipitation scenarios to develop a more robust, higher resolution likelihood assessment for $\mathrm{AFB}_{1}$ contamination, and so avoid risks of maladaptation. With higher resolution climate models, it would also be possible to more confidently assess risk at a more granular level, such as using the six established agro-ecological zones of Malawi. This more detailed assessment would better align the risk assessment with regional agricultural strategy development. 


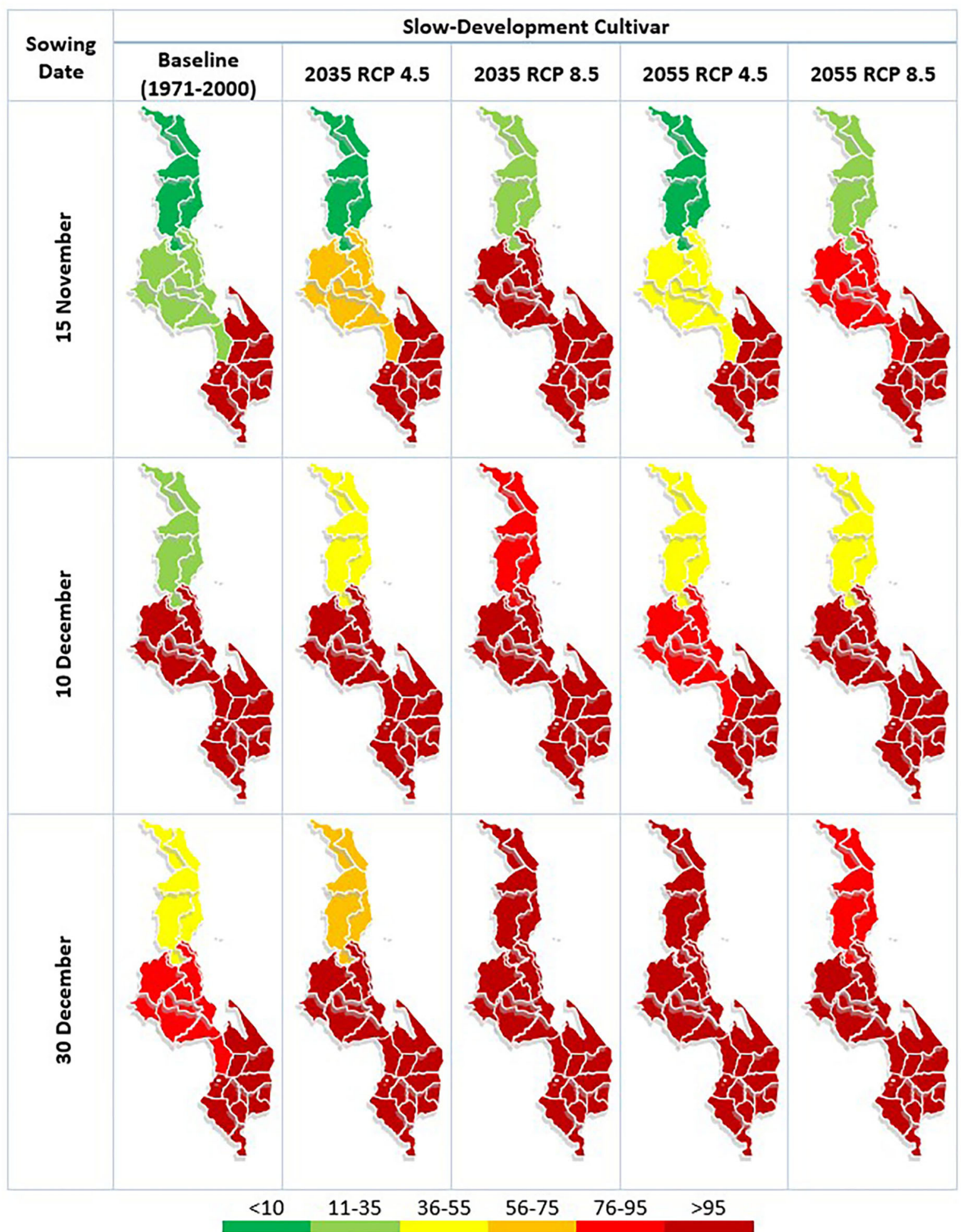

FIGURE 3 | AFI (Aflatoxin risk index) for slow-developing maize variety in each region of Malawi under differing climatic conditions and sowing dates. The first of the five rows represents the AFI under the baseline climate condition (1971-2000), the second and third row represent this risk associated with the 2035 (2020-2049) climate period under Representative Concentration Pathway (RCP) 4.5 and 8.5, respectively, and the final two rows represent this risk associated with the 2055 (2040-2069) climate period under RCP 4.5 and 8.5, respectively. The three columns represent the different sowing dates considered: 15 November, 10 December and 30th of December. The index at the bottom places the AFI results into color bands, with the deepest red indicating AFI levels which are consistent with exceedances of the EU threshold for $\mathrm{AFB}_{1}(5 \mu \mathrm{g} / \mathrm{kg})$ contamination in food. 


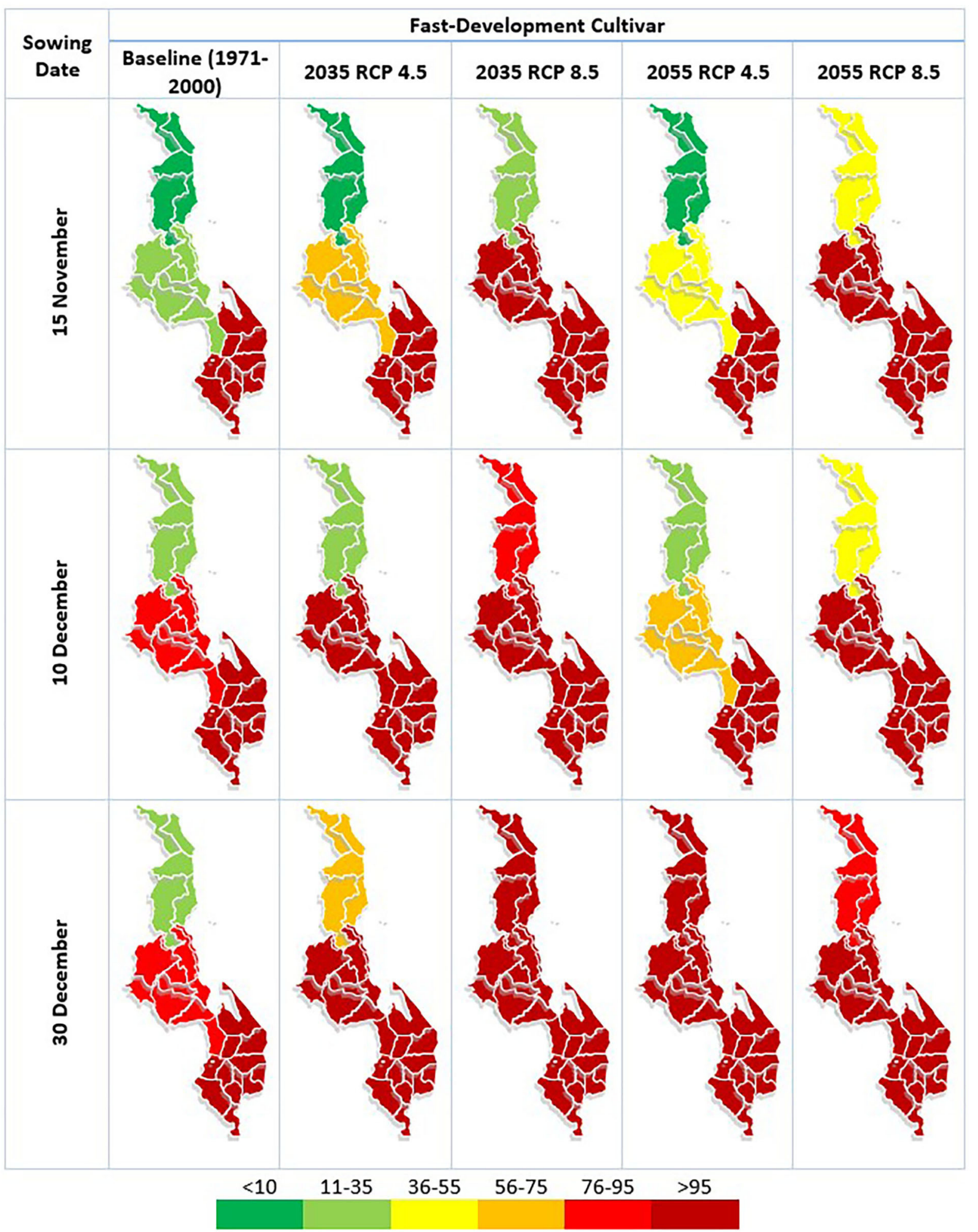

FIGURE 4 | AFI risk for fast-developing maize variety in each region of Malawi under differing climatic conditions and sowing dates. The first of the five rows represents the AFI risk under the baseline climate condition (1971-2000), the second and third row represent this risk associated with the 2020-2049 climate under RCP 4.5 and 8.5, respectively, and the final two rows represent this risk associated with the 2040-2069 climate under RCP 4.5 and 8.5, respectively. The three columns represent the different sowing dates assessed: 15 November, 10 December and 30th of December. The index at the bottom places the AFI results into color bands, with the deepest red indicating AFI levels which are consistent with exceedances of the EU threshold for AFB 1 contamination in food. 
Our research does suggest that changing to a faster developing variety of maize may limit the risk of $\mathrm{AFB}_{1}$ contamination at the time of harvest in parts of the country. However, this is not a solution for most of the maize growing areas and even where it is, it may not lead to lower contamination risk at the point of maize consumption. This study only looks at the cumulative risk index up to the point of harvest, however if A. flavus is present on the crop at the time of harvest or becomes contaminated with spores post-harvest, it is likely to keep growing and metabolizing toxins, particularly if storage conditions are not optimized (Channaiah and Maier, 2014; Neme and Mohammed, 2017; Mahuku et al., 2019). Erratic rainfall patterns, which are typical for Malawi, and social issues including theft of food crops before harvest, often lead to early harvesting (Matumba et al., 2014a). The crops are then frequently stored before adequate drying for extended periods of time and in facilities with inadequate or non-existent temperature and moisture control. When grain is stored with humidity and temperature suitable for fungal activity, these factors promote the further growth of molds and leads to mycotoxin production. Aflatoxin synthesis is very rapid when grain humidity is lower than 28-30\% (Payne et al., 1988; Giorni et al., 2016), and these conditions are consistent with the common water content of post-harvest maize without adequate drying. The issue of postharvest contamination in a changing climate is therefore one that requires urgent examination in Malawi.

In addition to the need for research to be expanded to include post-harvest phases, research is required to understand how climate change will impact the contamination risk of other mycotoxins on maize, as well as the impact on other food crops. Despite the significant exposure risk and vulnerability of the population, $\mathrm{AFB}_{1}$ and other mycotoxin contamination does not yet appear to be a high priority from a public health policy standpoint in Malawi. While regulations limiting aflatoxins concentrations in food stuffs do exist, they only apply to products being exported or sold in supermarkets, and no regulation currently exists for other mycotoxins (Mwalwayo and Thole, 2016). Strict mycotoxin regulations do however exist in most developed countries which means that only the least contaminated crops can be exported, and the more contaminated foodstuffs are kept for local consumption (Matumba et al., 2015; Mwalwayo and Thole, 2016; Misihairabgwi et al., 2017).

Regulation on its own may not solve this issue as it would be likely to have little impact on the large quantity of subsistencebased farming in Malawi. Only 20 percent of maize farmers produce enough to sell their produce, with the remaining farmers only producing enough for their household's needs (Denning et al., 2009; Mwalwayo and Thole, 2016). Ambler et al. (2017) found that farmers who reported their crop to be damaged (loss of quality) predominantly did not dispose of it, but instead diverted the crop from sale and seed to instead use for their own consumption. The underlying food security and poverty issues in Malawi are compounded by undiversified diets, and an inadequate or incomplete knowledge on the risks associated with mycotoxins in the general population. A study by Matumba et al. (2016) found that while $88 \%$ of the population understood that molds posed a risk to human health, few understood what that danger was, and half believed that any toxins would be destroyed by cooking, which is generally not the case (Bullerman and Bianchini, 2007). Therefore, with insufficient knowledge on the impacts of ingesting moldy food, and most farmers selling their best product, the food remaining for household consumption is often the grain with the lowest quality and the highest probability of mycotoxin contamination (Mwalwayo and Thole, 2016).

Thus far, there have been no serious mycotoxicosis ${ }^{5}$ outbreaks reported in Malawi, possibly due to the limited reporting of cause of death and the difficulty of assigning causality to some aflatoxin affects, like immunosuppression, to the toxic ingestion. However, outbreaks have occurred in neighboring countries with similar climates (Mwalwayo and Thole, 2016), and studies indicate that the Malawian population is already consuming contaminated food (Doko et al., 1996; Matumba et al., 2009, 2014b,d; Monyo et al., 2012; Probst et al., 2014; Matumba et al., 2015; Mwalwayo and Thole, 2016). Worryingly, Malawi has very high rates of cancers which are known to be linked to mycotoxin exposure (The Global Cancer Observatory, 2019). However, while the correlation exists, no systematic study has been carried out to determine the causal factors or fully explore links with mycotoxin exposure and incidence of cancer or other health issues in Malawi (Mwalwayo and Thole, 2016).

Our study finds projected climate change is expected to cause the main food crop in Malawi, maize, to become more contaminated, with dangerous levels of $\mathrm{AFB}_{1}$ at the point of harvest in regions of the country that haven't historically faced this challenge. Unless adaptation or mitigation measures are put in place to improve or change storage, consumption and legislative conditions, this will likely lead to higher levels of toxins to be present in foods at the point of consumption. From a risk assessment perspective, the results of this paper represent a communication tool for stakeholders, including policy makers, to highlight the need for education and awareness of this risk. The approach followed in this study can significantly support emerging countries like Malawi to reduce local population exposure to aflatoxins, and therefore improve human and livestock health. Future research is required to explore what mitigation and adaptation measures are available and appropriate for use in Malawi, and the impact these may have on $\mathrm{AFB}_{1}$ contamination risk of Malawian maize crops. Further analysis of post-harvest contamination of maize, as well as the impact of climate change on other mycotoxins and food crops is now also urgently required.

\section{DATA AVAILABILITY STATEMENT}

The datasets presented in this study can be found in online repositories. The names of the repository/repositories and accession number(s) can be found at: https:/github.com/ ErikaWarnatzsch/Maize-Aflatoxin-Risk.

\footnotetext{
${ }^{5}$ Mycotoxicosis is poisoning caused by exposure to mycotoxins.
} 


\section{AUTHOR CONTRIBUTIONS}

EW helped conceptualize the research plan, responsible for data curation, formal analysis, investigation, validation of the methodologies applied, and analyzed all results, created all tables and figures, and was responsible for writing the original draft and managing all reviews and edits of subsequent versions. DR acted as supervisor during this research, helping to conceptualize the research plan, and supported the results analysis. MC and $\mathrm{PB}$ were responsible for the application and validation of the methodologies described in section Aflatoxin Contamination Risk Assessment and helped analyze the results described in section Changes in Aflatoxin B1 Contamination Risk of this paper. All authors reviewed and edited draft manuscripts and gave final approval for submission of the manuscript for publication.

\section{FUNDING}

EW was funded by a Natural Environment Research Council (NERC) doctoral training partnership grant (NE/L002558/1).

\section{REFERENCES}

Adeyeye, S. A. O. (2016). Fungal mycotoxins in foods: a review. Cogent Food Agric. 2:1213127. doi: 10.1080/23311932.2016.1213127

Allen, R. G., Pereira, L. S., Raes, D., and Smith, M. (1998a). FAO PenmanMonteith Equation. Crop Evapotranspiration - Guidelines for Computing Crop Water Requirements. Rome: FAO.

Allen, R. G., Pereira, L. S., Raes, D., and Smith, M. (1998b). Meteorological Data. Crop Evapotranspiration - Guidelines for Computing Crop Water Requirements. Rome: FAO.

Almeida, R. M. A., Corrêa, B., Xavier, J. G., Mallozzi, M. A. B., Gambale, W., and Paula, C. R. (1996). Acute effect of aflatoxin B1 on different inbred mouse strains II. Mycopathologia 133, 23-29. doi: 10.1007/BF00437095

Ambler, K., De Brauw, A., and Godlonton, S. (2017). Measuring Postharvest Losses at the Farm Level in Malawi. Washington, DC: International Food Policy Research Institute (IFPRI). doi: 10.1111/1467-8489.12237

Arya, A., Mckilligan, H., and Marsili, R. (2005). Special Report: FAO/WFP Crop and Food Supply Assessment Mission to Malawi. Rome: FAO and WFP Secretariats.

Battilani, P., Barbano, C., and Piva, G. (2008). Aflatoxin B-1 contamination in maize related to the aridity index in North Italy. World Mycotoxin J. 1, 449-456. doi: 10.3920/WMJ2008.x043

Battilani, P., Camardo Leggieri, M., Rossi, V., and Giorni, P. (2013). AFLA-maize, a mechanistic model for Aspergillus flavus infection and aflatoxin B1 contamination in maize. Comput. Electron. Agricu. 94, 38-46. doi: 10.1016/j.compag.2013.03.005

Battilani, P., Toscano, P., Van Der Fels-Klerx, H. J., Moretti, A., Camardo leggieri, M., Brera, C., et al. (2016). Aflatoxin B1 contamination in maize in Europe increases due to climate change. Sci. Rep. 6:24328. doi: 10.1038/ srep 24328

Bennett, J. W., and Klich, M. (2003). Mycotoxins. Clin. Microbiol. Rev. 16, 497-516. doi: 10.1128/CMR.16.3.497-516.2003

Bhat, R. V., and Miller, J. D. (1991). "Mycotoxins and food supply," in Food, Nutrition and Agriculture, eds P. Lunven, K. Richmond, J. Lupien, M. Papetti, F. Simmersbach, and B. Thompson (Rome: FAO), 27-31.

Bullerman, L. B., and Bianchini, A. (2007). Stability of mycotoxins during food processing. Int. J. Food Microbiol. 119, 140-146. doi: 10.1016/j.ijfoodmicro.2007.07.035

Camardo Leggieri, M., Van, F. K., Der, I., and Battilani, P. (2013). Cross-validation of predictive models for deoxynivalenol in wheat. World Mycotoxin J. 6, 389-397. doi: 10.3920/WMJ2013.1546

\section{ACKNOWLEDGMENTS}

We thank all the institutions listed in Supplementary Tables 1, 2 to this article for making the observed data and models available. We also thank David Jackson, Sam Bowers, Dr. Magnus Hagdorn, Dr. Massimo Bollasina, Rachel Bartlett, and all the members on Stack Overflow for all their help with Python troubleshooting. We also thank the FAO for developing and maintaining the AquaCrop model in the public domain.

\section{SUPPLEMENTARY MATERIAL}

The Supplementary Material for this article can be found online at: https://www.frontiersin.org/articles/10.3389/fsufs.2020. 591792/full\#supplementary-material

The Supplementary Information can be found in the author's GitHub directory: https://github.com/ErikaWarnatzsch/MaizeAflatoxin-Risk.

Channaiah, L. H., and Maier, D. E. (2014). "Best stored maize managciement practices for the prevention of mycotoxin contamination," in Mycotoxin reduction in grain chains, eds J. F. LESLIE and A. F. Logrieco (Oxford: John Wiley \& Sons, Inc.), 78-88. doi: 10.1002/9781118832790.ch6

Chipinga, E. P. J. (2014). Survey of Fungi and Mycotoxins in Food Commodities in Malawi With Particular Reference to Chronic Diseases (M.Sc. Technology). University of Johanesburg, Johannesburg, South Africa.

De Wolf, E. D., Madden, L. V., and Lippis, P. E. (2003). Risk assessment model for wheat Fusarium head blight epidemics based on within-season weather data. Phytopathology 93, 428-435. doi: 10.1094/PHYTO.2003.93.4.428

Denning, G., Kabambe, P., Sanchez, P., Malik, A., Flor, R., Harawa, R., et al. (2009). Input subsidies to improve smallholder maize productivity in Malawi: towards an African green revolution. PLos Biol. 7:e1000023. doi: 10.1371/journal.pbio.1000023

Doko, M. B., Canet, C., Brown, N., Sydenham, E. W., Mpuchane, S., and Siame, B. A. (1996). Natural Co-occurrence of Fumonisins and Zearalenone in Cereals and Cereal-Based foods from Eastern and Southern Africa. J. Agric. Food Chem. 44, 3240-3243. doi: 10.1021/jf960257+

Eskola, M., Kos, G., Elliott, C. T., Haj Š Lov Á, J., Mayer, S., and Krska, R. (2019). Worldwide contamination of food-crops with mycotoxins: validity of the widely cited 'FAO Estimate' of 25\%. Crit. Rev. Food Sci. Nutr. 60, 2773-2789. doi: 10.1080/10408398.2019.1658570

EU (2006). Commission Regulation (EC) No 1881/2006 of 19 December 2006 Setting Maximum Levels for Certain Contaminants in Foodstuffs (Text With EEA Relevance). Brussels: The European Commission.

EU (2010). Commission Regulation (EU) No 165/2010 of 26 February 2010 Amending Regulation (EC) No 1881/2006 Setting Maximum Levels for Certain Contaminants in Foodstuffs as Regards Afflatoxins (Text With EEA Relevance). Brussels: The European Commission.

EU (2014). Commission Implementing Regulation (EU) No 884/2014 of 13 August 2014 Imposing Special Conditions Governing the Import of Certain Feed and Food From Certain third Countries Due to Contamination Risk From Aflatoxins and Repealing Regulation (EC) No 1152/2009 Text With EEA Relevance. Brussels: The European Commission.

FAOSTAT (2018). Food Balance Sheets. Rome: FAO. Available online at: http:// www.fao.org/faostat/en/\#data/FBS (accessed March 05, 2018).

Giorgi, F., Jones, C., and Asrar, G. R. (2009). Addressing climate information needs at the regional level: the CORDEX framework. 58, 175-183.

Giorni, J., Bertuzzi, T., and Battilani, P. (2016). Aflatoxin in maize, a multifaceted answer of Aspergillus flavus governed by weather, host-plant 
and competitor fungi. J. Cereal Sci. 70, 256-262. doi: 10.1016/j.jcs.2016. 07.004

Hussein, H. S., and Brasel, J. M. (2001). Toxicity, metabolism and impact of mycotoxins on humans and animals. Toxicology 167, 101-134. doi: 10.1016/S0300-483X(01)00471-1

IHME (2018). Malawi. Seattle, WA: Institute for Health Metrics and Evaluation. Available online at: http://www.healthdata.org/malawi (accessed March 29, 2018).

Jolly, P. E. (2014). Aflatoxin: does it contribute to an increase in HIV viral load? Future Microbiol. 9, 121-124. doi: 10.2217/fmb.13.166

Kaminiaris, M. D., Leggieri, M. C., Tsitsigiannis, D. I., and Battilani, P. (2020). AFLA-PISTACHIO: development of a mechanistic model to predict the aflatoxin contamination of pistachio nuts. Toxins 12:445. doi: 10.3390/toxins12070445

Li, G., Messina, J., Peter, B. G., and Snapp, S. (2017). Mapping Land suitability for agriculture in Malawi: agricultural land suitability mapping. Land Degrad. Dev. 28, 2001-2016. doi: 10.1002/ldr.2723

Magan, N., Medina, A., and Aldred, D. (2011). Possible climate-change effects on mycotoxin contamination of food crops pre-and postharvest. Plant Pathol. 60, 150-163. doi: 10.1111/j.1365-3059.2010.02412.x

Mahuku, G., Sila Nzioki, H., Mutegi, C., Kanampiu, F., Narrod, C., and Makumbi, D. (2019). Pre-harvest management is a critical practice for minimizing aflatoxin contamination of maize. Food Control 96, 219-226. doi: 10.1016/j.foodcont.2018.08.032

Matumba, L., Christof, V. P., Ediage, E. N., and De Saeger, S. (2014a). Keeping mycotoxins away from the food: does the existence of regulations have any impact in Africa. Crit. Rev. Food Sci. Nutr. 57, 1584-1592. doi: 10.1080/10408398.2014.993021

Matumba, L., Monjerezi, M., Biswick, T., Mwatseteza, J., Makumba, W., Kamangira, D., et al. (2014b). A survey of the incidence and level of aflatoxin contamination in a range of locally and imported processed foods on Malawian retail market. Food Control 39, 87-91. doi: 10.1016/j.foodcont.2013.09.068

Matumba, L., Monjerezi, M., Chriwa, E., Lakudzala, D., and Mumba, P. (2009). Natural occurrence of AFB1 in maize and effect of traditional maize flour production on AFB1 reduction in Malawi. Afr. J. Food Sci. 3, 413-425. doi: $10.5897 /$ AJFS.9000195

Matumba, L., Monjerezi, M., Kankwamba, H., Njoroge, S. M. C., Ndilowe, P., Kabuli, H., et al. (2016). Knowledge, attitude, and practices concerning presence of molds in foods among members of the general public in Malawi. Mycotoxin Res. 32, 27-36. doi: 10.1007/s12550-015-0237-3

Matumba, L., Sulyok, M., Monjerezi, M., Biswick, T., and Krska, R. (2014c). Fungal metabolites diversity in maize and associated human dietary exposures relate to micro-climate patterns in Malawi. World Mycotoxin J. 8, 269-282. doi: 10.3920/WMJ2014.1773

Matumba, L., Van Poucke, C., Biswick, T., Monjerezi, M., Mwatseteza, J., and De Saeger, S. (2014d). A limited survey of mycotoxins in traditional maize based opaque beers in Malawi. Food Control 36, 253-256. doi: 10.1016/j.foodcont.2013.08.032

Matumba, L., Van Poucke, C., Monjerezi, M., Ediage, E. N., and De Saeger, S. (2015). Concentrating aflatoxins on the domestic market through groundnut export: a focus on Malawian groundnut value and supply chain. Food Control 51, 236-239. doi: 10.1016/j.foodcont.2014.11.035

Medina, A., Akbar, A., Baazeem, A., Rodriguez, A., and Magan, N. (2017). Climate change, food security and mycotoxins: do we know enough? Fungal Biol. Rev. 31, 143-154. doi: 10.1016/j.fbr.2017.04.002

Medina, A., Rodriguez, A., and Magan, N. (2014). Effect of climate change on Aspergillus flavus and aflatoxin B1 production. Front. Microbiol. 5:348. doi: $10.3389 /$ fmicb. 2014.00348

Met Malawi (2006). Climate of Malawi: Temperature Maps. Ministry of Natural Resources, Energy and Environment; Department of Climate Change and Meteorological Services. Available online at: https://www.metmalawi.com/ climate/temperature.php (accessed September 03, 2019).

Met Office (2018). UKCP18 Guidance: Bias Correction. Available online at: https://www.metoffice.gov.uk/binaries/content/assets/metofficegovuk/pdf/ research/ukcp/ukcp18-guidance---how-to-bias-correct.pdf (accessed August 01, 2019).

Misihairabgwi, J. M., Ezekiel, C. N., Sulyok, M., Shephard, G. S., and Krska, R. (2017). Mycotoxin contamination of foods in Southern Africa: a 10-year review (2007-2016). Crit. Rev. Food Sci. Nutr. 58, 43-58. doi: 10.1080/10408398.2017.1357003

Mittal, N., Vincent, K., Conway, D., Archer Van Garderen, E., Pardoe, J., Todd, M. T., et al. (2017). Future Climate Projections for Malawi. Cape Town: FCFA. Country Climate Brief.

Monyo, E. S., Njoroge, S. M. C., Coe, R., Osiru, M., Madinda, F., Waliyar, F., et al. (2012). Occurrence and distribution of aflatoxin contamination in groundnuts (Arachis hypogaea L) and populatioon density of Aflatoxigenic Aspergilli in Malawi. Crop Protect. 42, 149-155. doi: 10.1016/j.cropro.2012. 07.004

Mwalwayo, D. S., and Thole, B. (2016). Prevalence of aflatoxin and fumonisins $(\mathrm{B} 1+\mathrm{B} 2)$ in maize consumed in rural Malawi. Toxicol. Rep. 3, 173-179. doi: 10.1016/j.toxrep.2016.01.010

Neme, K., and Mohammed, A. (2017). Mycotoxin occurrence in grains and the role of postharvest management as a mitigation strategies. A review. Food Control 78, 412-425. doi: 10.1016/j.foodcont.2017.03.012

Ngongondo, C., Xu, C. Y., Tallaksen, L. M., and Alemaw, B. (2012). Evolution of the FAO Penman-Monthith, Preistley-Taylor and Hargreaves models for estimating reference evapotranspiration in southern Malawi. Hydrol. Res. 44, 706-722. doi: 10.2166/nh.2012.224

Nikulin, G., Jones, C., Giorgi, F., Asrar, G., Büchner, M., Cerezo-Mota, R., et al. (2012). Precipitation climatology in an ensemble of CORDEX-Africa regional climate simulations. Am. Meteorol. Soc. J. Clim. 25, 6057-6078. doi: 10.1175/JCLI-D-11-00375.1

PACA (2020). Strengthening Aflatoxin Control in Malawi: Policy Recommendations. Addis Ababa: Partnership for Aflatoxin Control in Africa (PACA).

Paterson, R. R. M., and Lima, N. (2010). How will climate change affect mycotoxins in food? Food Res. Int. 43, 1902-1914. doi: 10.1016/j.foodres.2009. 07.010

Payne, G. A., and Brown, M. P. (1998). Genetics and Physiology of aflatoxin biosynthesis. Annu. Rev. Phytopathol. 36, 329-362. doi: 10.1146/annurev.phyto.36.1.329

Payne, G. A., Hagler, W. M. J., and Adkins, C. R. (1988). Aflatoxin accumulation in inoculated ears of field-grown maize. Plant Dis. 72, 422-424. doi: 10.1094/PD-72-0422

Peraica, M., Radi, C., B., Luci, C., A., and Pavlovi, C., M. (1999). Toxic effects of mycotoxins in humans. Bull. World Health Organ. 77, 754-766.

Probst, C., Bandyopadhyay, R., and Cotty, P. J. (2014). Diversity of aflatoxinproducing fungi and their impact on food safety in sub-Saharan Africa. Int. J. Food Microbiol. 174, 113-122. doi: 10.1016/j.ijfoodmicro.2013.12.010

Rushing, B. R., and Selim, M. I. (2019). Aflatoxin B1: a review on metabolism, toxicity, occurrence in food, occupational exposure, and detoxification methods. Food Chem. Toxicol. 124, 81-100. doi: 10.1016/j.fct.2018.11.047

Santini, A., and Ritieni, A. (2013). Aflatoxins: Risk, Exposure and Remediation. In: Aflatoxins - Recent Advances and Future Prospects, ed M. Razzaghi-Abyaneh (London: Intech). doi: 10.5772/52866

Sentelhas, P. C., Della Marta, A., Orlandini, S., Santos, E. A., Gillespie, T. J., and Gleason, M. L. (2008). Suitability of relative humidity as an estimator of leaf wetness duration. Agric. Forest Meteorol. 148, 392-400. doi: 10.1016/j.agrformet.2007.09.011

Stepman, F. (2018). Scaling-Up the impact of aflatoxin research in Africa. The role of social sciences. Toxins 10:136. doi: 10.3390/toxins10040136

The Global Cancer Observatory (2019). Malawi. The World Health Organization. International Agency for Research on Cancer. Available online at: https:// gco.iarc.fr/today/data/factsheets/populations/454-malawi-fact-sheets.pdf (accessed November 05, 2020).

Udomkun, P., Nimo Wiredu, A., Nagle, M., Bandyopadhyay, R., Muller, J., and Vanlauwe, B. (2017). Mycotoxins in Sub-Saharan Africa: present situation, socio-economic impact, awareness, and outlook. Food Control 72, 110-122. doi: 10.1016/j.foodcont.2016.07.039

Wang, Y. M., Namaona, W., Gladden, L. A., Traore, S., and Deng, L. T. (2011). Comparative study on estimating reference evapotranspiration under limited climate data condition in Malawi. Int. J. Phys. Sci. 6, 2239-2248. doi: 10.5897/IJPS11.166

Warnatzsch, E. A., and Reay, D. S. (2019). Temperature and precipitation change in Malawi: evaluation of CORDEX-Africa climate simulations for climate change impact assessments and adaptation planning. Sci. Total Environ. 654, 378-392. doi: 10.1016/j.scitotenv.2018.11.098 
Warnatzsch, E. A., and Reay, D. S. (2020). Assessing climate change projections and impacts on central Malawi's maize yield: the risk of maladaptation. Sci. Total Environ. 711:134845. doi: 10.1016/j.scitotenv.2019.134845

Conflict of Interest: The authors declare that the research was conducted in the absence of any commercial or financial relationships that could be construed as a potential conflict of interest.
Copyright (c) 2020 Warnatzsch, Reay, Camardo Leggieri and Battilani. This is an open-access article distributed under the terms of the Creative Commons Attribution License (CC BY). The use, distribution or reproduction in other forums is permitted, provided the original author(s) and the copyright owner(s) are credited and that the original publication in this journal is cited, in accordance with accepted academic practice. No use, distribution or reproduction is permitted which does not comply with these terms. 